\title{
Behavioral Response of the Brown Marmorated Stink Bug (Hemiptera: Pentatomidae) to Semiochemicals Deployed Inside and Outside Anthropogenic Structures During the Overwintering Period
}

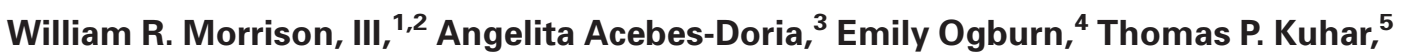 \\ James F. Walgenbach, ${ }^{4}$ J. Christopher Bergh, ${ }^{3}$ Louis Nottingham, ${ }^{6}$ Anthony Dimeglio, ${ }^{5}$ \\ Patricia Hipkins, ${ }^{5}$ and Tracy C. Leskey ${ }^{7}$
}

${ }^{1}$ USDA, Agricultural Research Service, Center for Grain and Animal Health Research, 1515 College Ave., Manhattan, KS 66502 (william.morrison@ars.usda.gov), ²Corresponding author, email: william.morrison@ars.usda.gov, ${ }^{3}$ Virginia Tech, Alson H. Smith, Jr. Agricultural Research and Extension Center, Winchester, VA 22602 (aacebes@vt.edu; cbergh@vt.edu), ${ }^{4}$ Department of Entomology \& Plant Pathology, North Carolina State University, Mills River, NC 28759 (ecogburn@ncsu.edu; jim_walgenbach@ncsu.edu), ${ }^{5}$ Department of Entomology, Virginia Tech, Blacksburg, VA 24061 (tkuhar@vt.edu; tonyd87@vt.edu; phipkins@vt.edu), ${ }^{6}$ Tree Fruit Research and Extension Center, Washington State University, Wenatchee, WA 98801 (louisn@vt.edu) and ${ }^{7}$ USDA, Agricultural Research Service, Appalachian Fruit Research Station, 2217 Wiltshire Rd., Kearneysville, WV 25430 (tracy.leskey@ars.usda.gov)

Subject Editor: John Trumble

Received 4 January 2017; Editorial decision 28 February 2017

\begin{abstract}
The brown marmorated stink bug, Halyomorpha halys (Stål), is an invasive species from Asia capable of causing severe agricultural damage. It can also be a nuisance pest when it enters and exits anthropogenic overwintering sites. In recent years, pheromone lures and traps for $H$. halys have been developed and used to monitor populations in field studies. To date, no study has investigated the applicability of these monitoring tools for use indoors by building residents during the overwintering period. Herein, we 1) assessed when in late winter (diapause) and spring (postdiapause) $H$. halys begins to respond to its pheromone (10,11-epoxy-1-bisabolen-3-ol), 2) evaluated whether pheromone-based tools can be used reliably for monitoring $H$. halys adults in unheated and heated buildings, and 3) elucidated the potential for indoor management using pheromone-baited traps. A 2-yr trapping study suggested that $H$. halys began to respond reliably to pheromone-baited traps after a critical photoperiod of $13.5 \mathrm{~h}$ in the spring. Captures before that point were not correlated with visual counts of bugs in buildings despite robust populations, suggesting currently available pheromone-baited traps were ineffective for surveillance of diapausing $H$. halys. Finally, because baited traps captured only $8-20 \%$ of the adult $H$. halys known to be present per location, they were not an effective indoor management tool for overwintering $H$. halys. Our study contributes important knowledge about the capacity of $H$. halys to perceive its pheromone during overwintering, and the ramifications thereof for building residents with nuisance problems.
\end{abstract}

Key words: Halyomorpha halys, indoor, urban, invasive species, monitoring

The brown marmorated stink bug, Halyomorpha halys (Stål) (Hemiptera: Pentatomidae), is a recent invasive species in the United States (Hoebeke and Carter 2003) and Europe (Haye et al. 2015). It has caused severe agricultural damage to a number of crops in the United States and has been detected in 43 states (Leskey et al. 2012a, Rice et al. 2014). During the late fall and winter, $H$. halys is also a significant nuisance for building residents and businesses, owing to its affinity for overwintering at high densities in anthropogenic structures. This has been especially true in the Mid-Atlantic region of the United States, where, for example, Inkley (2012) reported counting $>20,000 \mathrm{H}$. halys adults over a 3-mo observation period in a private residence in Maryland.

There have been extensive studies on developing a reliable system for trapping $H$. halys in vegetable and fruit crops. For example, Leskey et al. (2012b) found that a 1.22-m, black pyramid trap was the most effective trap design (when baited with methyl $(2 E, 4 E, 6 Z)$ decatrienoate) for sampling $H$. halys in orchards, compared with traps of other shapes and colors. Since then, a more attractive bait 
has been developed for $H$. halys adults and nymphs, composed of the two-component $H$. halys aggregation pheromone (SSRS and RSRS isomers of 10,11-epoxy-1-bisabolen-3-ol) identified by Khrimian et al. (2014) and includes the synergistic compound (E,E,Z)-2,4,6-methyl decatrienoate (MDT; Weber et al. 2014). Related stereoisomers from the parent compound, 10,11-epoxy-1bisabolen-3-ol, that are not found in natural volatile collections from male $H$. halys have also been shown to have biological activity in field-deployed traps (Leskey et al. 2015b). It is known that the $H$. halys aggregation pheromone is attractive to adults season-long, while MDT is most attractive to adults in the latter part of the growing season (Leskey et al. 2015a). In addition, MDT seems to be attractive to nymphs throughout the growing season (Leskey et al. 2015a). When the $H$. halys aggregation pheromone and MDT were combined in traps deployed in agricultural landscapes during the growing season, there were reliable, season-long captures, even in areas with low pest density (Leskey et al. 2015a). More recently, other kinds of traps baited with these olfactory stimuli were shown to be effective, including small $(0.29 \mathrm{~m})$ black pyramids (Morrison et al. 2015). Light traps (Leskey et al. 2015c, Nielsen et al. 2013) have also been evaluated for sampling $H$. halys in agricultural settings, but their reliability is adversely affected by abiotic constraints such as low nighttime temperatures.

Knowing when and under what conditions adult $H$. halys starts and stops responding to its pheromone in spring and fall, respectively, has clear management implications for building residents, growers, and regulatory agencies in countries interested in the biosecurity issues associated with the unintentional transport of adults overwintering in international cargo. During the late fall, as adult $H$. halys start to disperse to overwintering sites, usually to either anthropogenic structures embedded in the landscape or standing dead trees (Lee et al. 2015), they appear to cease responding to both the $H$. halys aggregation pheromone and MDT. In the spring, when $H$. halys adults emerge from overwintering sites, they seem to disperse from the vicinity of the overwintering site before responding to these olfactory stimuli (Bergh et al. 2017). However, the timing of this behavioral shift in the spring is not clear. One potential trigger could be diapause termination triggered by a critical photoperiod, which is likely around $13.5 \mathrm{~h}$ for $H$. halys (Nielsen et al. 2016).

Although growers currently have monitoring tools that may help inform their management of $H$. halys during the growing season (Short et al. 2016), neither building residents, managers of large warehouses, nor those involved in the international shipping industry have an equivalent tool during the overwintering period when the pest frequently causes nuisance problems. Furthermore, it is uncertain whether the pheromone-based tools developed for growers can be used for surveillance in buildings, and whether captures in pheromone-baited traps would adequately monitor indoor populations of $H$. halys.

In addition to the lack of appropriate monitoring tools, building residents and businesses currently lack sufficient management tactics to provide protection from nuisance problems associated with the presence of $H$. halys. Some work has shown that certain insecticides registered for use in urban environments have fairly good residual activity when applied to window screening to prevent entry by H. halys (Mooneyham et al. 2016). Aigner and Kuhar (2016) showed that lethal heat treatments of $45^{\circ} \mathrm{C}$ for an hour or $50^{\circ} \mathrm{C}$ for 15 min can cause $100 \%$ mortality of $H$. halys in cars intended for shipment. Although well-suited for the shipping industry, the use of heat in a building setting is cost-intensive. A citizen scientist project that sought to identify the most effective indoor light trap found that an aluminum pan partially filled with soapy water and a desk lamp suspended overhead captured the greatest number of adult $H$. halys, ranging up to 144 adults per week (Aigner and Kuhar 2016). Morrison et al. (2017a) established that natural enemies in homes, particularly spiders, may contribute to the mortality of $H$. halys during their overwintering period, although biological control of $H$. halys in structures has not been shown to adequately control their populations, and other tactics are needed. As a result, it is important to test the ability of pheromone-based traps to serve as an aid in controlling $H$. halys inside anthropogenic structures, owing to their known ability to attract and capture $H$. halys adults in agricultural settings.

The goals of this study were to use pyramid traps baited with the $H$. halys aggregation pheromone and pheromone synergist, MDT to: 1) assess when in late winter (diapause) and spring (postdiapause) that $H$. halys begin responding to its pheromone, 2) evaluate whether these are reliable for monitoring $H$. halys in unheated and heated buildings, and 3) test the potential for pheromone-baited traps to control H. halys inside anthropogenic structures.

\section{Materials and Methods}

\section{Study Sites}

In 2014, trapping experiments were performed at the Appalachian Fruit Research Station in Kearneysville, WV (see Table 1, AFRS, for GPS coordinates). In 2016, trapping experiments were performed in North Carolina, Virginia, and West Virginia (Table 1). Sites were chosen based on reliable access to buildings, availability of space, and representativeness of locations with severe $H$. halys nuisance problems. At these locations, trapping was performed in heated structures, unheated structures, and outside, or some combination of these (Table 1).

\section{Trap Design and Lures}

Traps deployed in heated and unheated structures for both years were 30.5-cm-tall, black pyramid traps (AgBio, Inc. Westminster, $\mathrm{CO})$. In agricultural settings, similar small pyramids have been shown to yield similar captures of adult $H$. halys to larger standard 1.22-m pyramid traps (Morrison et al. 2015). The pyramid traps for our study consisted of two pieces of plastic $(15.2 \mathrm{~cm}$ wide at the base, $2.5 \mathrm{~cm}$ wide at the top) that intersected each other at a right angle. A plastic collection jar ( 10.2 by 10.2 by $15.2 \mathrm{~cm}$; W by $\mathrm{L}$ by $\mathrm{H}$ ) was affixed at the apex of each. At the base of the collection jar was a 7.6-cm-wide funnel that connected to the pyramid base. Traps deployed outside of structures were large, black $1.22-\mathrm{m}$ pyramid traps (AgBio, Inc.), with the same collection jar and funnel described previously. The large pyramid trap consisted of two pieces of corrugated plastic, measuring $50.2 \mathrm{~cm}$ wide at the base and $3.8 \mathrm{~cm}$ at the top. Refer to Morrison et al. (2015) for more details about trap design.

In 2014, the traps were baited with gray rubber septa impregnated with $10.7 \mathrm{mg}$ of the $H$. halys aggregation pheromone, 10,11epoxy-1-bisabolen-3-ol, and a lure containing $66 \mathrm{mg}$ of MDT (AgBio, Inc.). The specifications for these lures were described in Leskey et al. (2015a,b). Lures were changed every 2 wk during the sampling period. To prevent the escape of adults, a 5 -cm piece of Hercon Vaportape II (Hercon Environmental, Emigsville, PA) containing $10 \%$ 2,2-dichlorovinyl dimethyl phosphate was placed in the collection jar and also changed every 2 wk during the sampling period.

In 2016, traps were baited with a $H$. halys monitoring lure (Trece Inc., Adair, OK) containing a combination of the H. halys 
Table 1. Summary of study sites for trapping studies in 2016

\begin{tabular}{|c|c|c|c|c|c|c|c|c|c|c|}
\hline \multirow[t]{2}{*}{ Site } & \multirow[t]{2}{*}{ County } & \multirow[t]{2}{*}{ State } & \multirow[t]{2}{*}{$\operatorname{Rep}(n)$} & \multirow[t]{2}{*}{ Sampled from } & \multicolumn{3}{|c|}{ Traps deployed in } & \multicolumn{2}{|c|}{ Visual counts in } & \multirow[t]{2}{*}{ GPS coordinates } \\
\hline & & & & & $\begin{array}{l}\text { Heated } \\
\text { structure }\end{array}$ & Outside & $\begin{array}{l}\text { Unheated } \\
\text { structure }\end{array}$ & $\begin{array}{c}\text { Heated } \\
\text { structure }\end{array}$ & $\begin{array}{l}\text { Unheated } \\
\text { structure }\end{array}$ & \\
\hline AFRS & Jefferson & WV & 3 & 26 Jan.-27 Jun. & $\mathrm{X}$ & $\mathrm{X}$ & $\mathrm{X}$ & $\mathrm{X}$ & $\mathrm{X}$ & $\begin{array}{l}39^{\circ} 21^{\prime} 19.13^{\prime \prime} \mathrm{N}, \\
77^{\circ} 52^{\prime} 36.42^{\prime \prime} \mathrm{W}\end{array}$ \\
\hline MHCREC & Henderson & NC & 3 & 9 Feb.-28 Jun. & $\mathrm{X}$ & $\mathrm{X}$ & $\mathrm{X}$ & $\mathrm{X}$ & $\mathrm{X}$ & $\begin{array}{l}35^{\circ} 25^{\prime} 32.21^{\prime \prime} \mathrm{N}, \\
82^{\circ} 33^{\prime} 39.20^{\prime \prime} \mathrm{W}\end{array}$ \\
\hline AREC & Frederick & VA & 3 & 5 Feb.-1 Jul. & $\mathrm{X}$ & $\mathrm{X}$ & & $\mathrm{X}$ & & $\begin{array}{l}39^{\circ} 6^{\prime} 40.24^{\prime \prime} \mathrm{N}, \\
78^{\circ} 16^{\prime} 48.99^{\prime \prime} \mathrm{W}\end{array}$ \\
\hline SVA1 & Montgomery & VA & 1 & 9 Mar.-29 Jun. & $\mathrm{X}$ & $\mathrm{X}$ & & $\mathrm{X}$ & & $\begin{array}{l}37^{\circ} 13^{\prime} 51.86^{\prime \prime} \mathrm{N}, \\
80^{\circ} 24^{\prime} 46.84^{\prime \prime} \mathrm{W}\end{array}$ \\
\hline SVA2 & Montgomery & VA & 1 & 17 Feb.-29 Jun. & $\mathrm{X}$ & $\mathrm{X}$ & & $\mathrm{X}$ & & $\begin{array}{l}37^{\circ} 13^{\prime} 52.60^{\prime \prime} \mathrm{N}, \\
80^{\circ} 27^{\prime} 12.50^{\prime \prime} \mathrm{W}\end{array}$ \\
\hline SVA3 & Giles & VA & 2 & 8 Feb.-27 Jun. & $\mathrm{X}$ & $\mathrm{X}$ & & $\mathrm{X}$ & & $\begin{array}{l}37^{\circ} 17^{\prime} 26.00^{\prime \prime} \mathrm{N}, \\
80^{\circ} 30^{\prime} 18.00^{\prime \prime} \mathrm{W}\end{array}$ \\
\hline
\end{tabular}

aggregation pheromone, 10-11-epoxy-1-bisabolen-3-ol (5 mg), and MDT $(50 \mathrm{mg})$. Lures were changed every $8 \mathrm{wk}$ during the sampling period. Deltamethin-infused netting ( 15.2 by $15.2 \mathrm{~cm}$; L by W; Zerofly, Vestergaard Frandsen Inc., Washington, D.C.) was used to line the funnel within the collection jar. The netting was substituted for the 2,2-dichlorovinyl dimethyl phosphate strips because it remains toxic longer (Kuhar et al. 2017). As a result, kill material did not have to be replaced throughout 2016.

\section{Trapping Experiment}

In 2014, six small pyramid traps were deployed in a heated structure (Site: AFRS, Table 1), with three traps baited and three unbaited (control). These were checked weekly for $H$. halys adult captures between 15 January and 24 February (diapause period) and between 19 April and 1 July 2014 (hereafter, postdiapause, shorthand for postdiapause termination). Numbers of $H$. halys captured in traps were sampled by counting all living and dead $H$. halys adults within the plastic container. The season was divided into two periods based on the critical photoperiod for diapause termination in $H$. halys, which corresponds to a day length of about $13.5 \mathrm{~h}$ (Nielsen et al. 2016). Traps were either placed in separate rooms of a building, or separated by at least $10 \mathrm{~m}$ when occurring in the same hallway or room. In addition, the total number of living and dead $H$. halys adults outside each trap was recorded weekly, by visual survey inspections of the associated spaces in the structure where traps were placed. The associated space for the visual survey was $281.5 \pm 72 \mathrm{~m}^{3}$ on an average, and took an average of $1.93 \pm 0.3 \mathrm{~s} / \mathrm{m}^{3}$ to search. After each weekly survey, alive and dead $H$. halys were removed from associated spaces.

\section{Trapping Experiment}

In 2016, traps were deployed at six sites in three US states (Table 1). At each site, six small pyramid traps (three baited and three unbaited controls) were placed in heated structures, and six large pyramid traps (three baited and three unbaited controls) were placed outside, within 1-5 m, of the associated structure, according to protocols in Leskey et al. (2015a). Moreover, at two sites, six small pyramid traps (three baited and three unbaited controls) were placed in single-story unheated structures (e.g., barns, equipment sheds, etc.). In addition, a visual survey of the associated observable spaces around traps in heated buildings were performed (as described above) in four single-story buildings and two two-story buildings, and the total number of $H$. halys adults (alive and dead) were recorded. On an average ( \pm SE), a $139.8 \pm 26 \mathrm{~m}^{3}$ area was searched associated with each trap, with an average search time of $1.03 \pm 0.1 \mathrm{~s} / \mathrm{m}^{3}$ (range: $0.10-2.5 \mathrm{~s} / \mathrm{m}^{3}$ ) across sites. Because the area associated with each trap was somewhat variable, the data were standardized on a per $\mathrm{m}^{3}$ basis, and calibrated to the average area sampled. Live and dead bugs were removed from the associated areas at all sampling sites on a weekly basis except Winchester, where live adults were left untouched. All trap positions were rotated and checked weekly from 26 January (earliest) to 1 July 2016 (latest) for captures of $H$. halys adults (Table 1). For analysis, the season was again divided into two periods: diapause (18 January-18 April) and postdiapause (19 April-27 June).

\section{Temperature Data}

Daily minimum, maximum, and mean outdoor temperatures were recorded from weather stations associated with AFRS, MHCREC, and AREC sites listed in Table 1 in 2014 and 2016. These weather stations were associated with each facility and took measurements on at least 10 -min intervals over a 24 -h period. The purpose of this information was to verify whether abiotic conditions were conducive to flight during the diapause and postdiapause sampling periods.

\section{Statistical Analysis}

To understand the effect of trap location and treatment on trap capture in 2014 and 2016, two repeated measures ANOVAs were used, with $H$. halys adult abundance as the response variable. In both years, the sampling treatment (baited traps, control traps), period (diapause or postdiapause), and their interaction were used as explanatory variables. In 2016, an additional explanatory variable, location (heated structure, unheated structure, or outside), was added to the model, and only first-order interactions were included. To account for the lack of independence between weekly samples, sampling week was used as the repeated measure. Inspection of residuals revealed deviations from the assumptions of normality, but logtransformations of the data corrected these. Upon a significant result from the ANOVA, Tukey's HSD was employed for pairwise comparisons. For this, and all other statistical tests, $\alpha=0.05$ was used. All statistical procedures were run in $\mathrm{R}$ Software ( $\mathrm{R}$ Core Team, 2016). 
To elucidate whether traps in 2014 and 2016 were reliably detecting adults as they emerged in the building, and to understand whether this varied by time of year, Spearman rank correlation was performed. Specifically, this was done between the weekly abundance of $H$. halys in the visual surveys and the mean weekly trap captures (for baited and unbaited traps separately) in both the diapause and the postdiapause period. These nonparametric procedures were used to account for low sample size and lack of normality.

\section{Results}

\section{Trapping Experiment}

Overall, a total of $372 \mathrm{H}$. halys adults were recorded in the associated areas outside traps, whereas only 14 and 60 adults were captured in control and baited small pyramid traps, respectively, over the sampling period. Significantly more adults were found, on an average, in areas surrounding traps than within traps, in both the diapause and postdiapause periods indoors (ANOVA: $F=55.6 ; \mathrm{df}=2,228 ; P<0.0001$; Fig. $1 \mathrm{~A}$ and $\mathrm{B})$. Specifically, there were $27-115$ times more adults recorded from visual surveys than in baited or unbaited traps, respectively, across the season. The period significantly influenced the abundance of $H$. halys (ANOVA: $F=48.22 ; \mathrm{df}=1,228 ; P<0.0001$ ), with over four times as many adults caught during the diapause than the postdiapause period. There was also a significant interaction between period and treatment (ANOVA: $F=24.2 ; \mathrm{df}=2,228$; $P<0.0001)$. In the diapause period, the baited traps did not capture significantly more $H$. halys than unbaited traps (Fig 1A; Tukey's HSD), while in the postdiapause period, baited traps captured over eight times more adults (Fig. 1B; Tukey's HSD).

During the diapause period, captures in both baited $(\rho=0.058$, $\mathrm{df}=5, P=0.913$; Fig. $2 \mathrm{~A})$ and unbaited $(\rho=0.441, \mathrm{df}=5, P=0.381$; Fig. 2 C) traps in heated buildings were not correlated with the abundance of $H$. halys adults found in associated areas outside of traps. However, during the postdiapause period, captures in baited

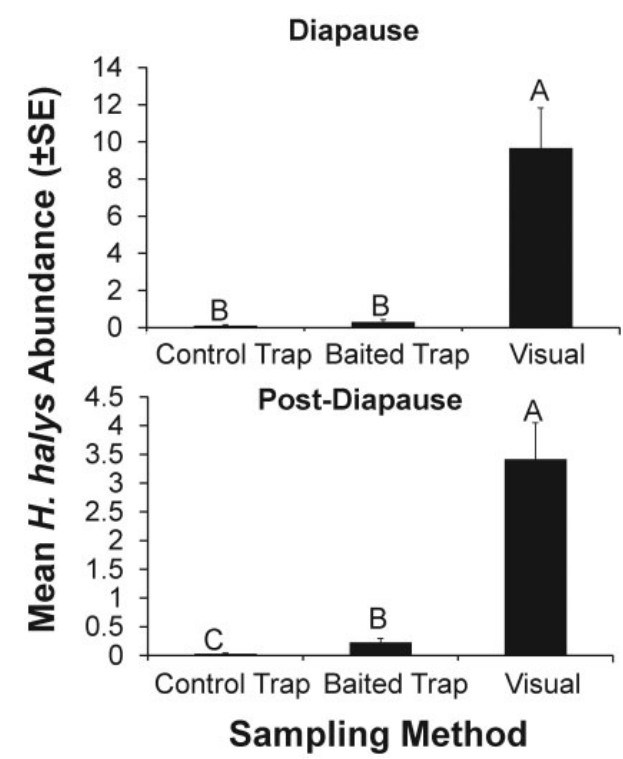

Fig. 1. Mean abundance of $H$. halys from trapping and visual survey data from within heated structures at the Appalachian Fruit Research Station in Kearneysville, WV, for the diapause (top panel) and postdiapause (bottom panel) periods in 2014. Bars that share letters are not significantly different from one another (Tukey's HSD, $\alpha=0.05$ ). The diapause period corresponds with time prior to the critical diapause termination cue of 13.5 -h photoperiod, while postdiapause are dates afterwards.
( $\rho=0.794, \mathrm{df}=11, P<0.002$; Fig. $2 \mathrm{~B})$ but not unbaited $(\rho=0.320$, $\mathrm{df}=11, P=0.311$; Fig. $2 \mathrm{D})$ pyramid traps in heated structures were correlated with the abundance of $H$. halys in associated hallways.

\section{Trapping Experiment}

In 2016, visual surveys of associated spaces outside of traps resulted in 592 adult $H$. halys recorded from heated buildings, whereas 156 and 62 adults were captured in baited and unbaited traps in the same buildings, respectively. By contrast, a total of nine adults were recorded from visual surveys in unheated buildings, but no individuals were captured in traps. In traps deployed outside, a total of 643 and 92 adults were captured in baited and unbaited control traps, respectively. The sampling location significantly influenced the abundance of $H$. halys adults found over the entire season (ANOVA: $F=7.04$; $\mathrm{df}=2,64 ; P<0.002$ ) and in each period individually (Fig. $3 \mathrm{~A}$ and B). On an average, there were about 4 and 48 times more adults captured in traps placed outside compared with those inside heated and unheated buildings, respectively. The sampling treatment (baited or unbaited traps, and visual sampling) significantly influenced the numbers of $H$. halys adults recorded $(F=5.70 ; \mathrm{df}=2,64 ; P<0.006)$. Overall, throughout both periods, the visual surveys yielded 3 and 17 times more adults than baited pheromone traps and unbaited traps, respectively. Moreover, the sampling period also significantly influenced the number of adult $H$. halys captured or recorded visually $(F=16.29$; $\mathrm{df}=1,64$; $P<0.0001$; Fig. $3 \mathrm{~A}$ and $\mathrm{B})$ and had a significant interaction with sampling location $(F=10.39 ; \mathrm{df}=2,64 ; P<0.0001)$ but not with treatment $(F=2.89 ; \mathrm{df}=2,64 ; P=0.06)$. Specifically, there were three to four times more adults in traps deployed outside and in unheated buildings during the postdiapause period than the diapause period. Notably, in the diapause period, visual surveys yielded almost 12 times more adult $H$. halys than in the baited traps in the same heated buildings (Fig. 3A), while in the postdiapause period, visual surveys yielded estimates that, on an average, were about five times greater (Fig. 3B). Throughout both periods, baited traps deployed outdoors captured 4-10 times more adult $H$. halys than unbaited traps in the same location (Fig. 3A and B). Finally, baited traps in heated buildings did not capture more adult $H$. halys than unbaited control traps (Fig. 4A).

During the diapause period in 2016, captures of $H$. halys adults in baited $(\rho=-0.126, \mathrm{df}=11, P=0.696$; Fig. $5 \mathrm{~A})$ and unbaited traps $(\rho=0.021, \mathrm{df}=11, P=0.948$; Fig. $5 \mathrm{~B})$ were not significantly correlated with visual counts in associated spaces outside of traps in heated buildings. In addition, captures of adults in baited traps during the same period $(\rho=-0.070, \mathrm{df}=11, P=0.828$; Fig. $6 \mathrm{~A})$ and unbaited traps $(\rho=-0.007, \mathrm{df}=11, P=0.982$; Fig. $6 \mathrm{~B})$ placed outside of buildings were not significantly correlated with visual counts of adults in heated buildings.

However, this pattern shifted in the 2016 postdiapause period. Specifically, captures of $H$. halys adults in baited $(\rho=0.723$, $\mathrm{df}=10, P<0.012$; Fig. $5 \mathrm{C})$ and unbaited traps $(\rho=0.646, \mathrm{df}=10$, $P<0.032$; Fig. 5D) in heated buildings were significantly correlated with visual counts of adults in associated hallways spaces. Moreover, captures of adults in baited $(\rho=0.706, \mathrm{df}=10$, $P<0.015$; Fig. 6C) and unbaited traps $(\rho=0.820, \mathrm{df}=10$, $P<0.002$; Fig. 6D) placed outside buildings were significantly correlated with visual counts of adults in heated buildings.

\section{Temperature Data}

In 2014, the mean ( \pm SE) outdoor temperature during the diapause period was $-2.1 \pm 0.07^{\circ} \mathrm{C}$, whereas during the postdiapause period, 


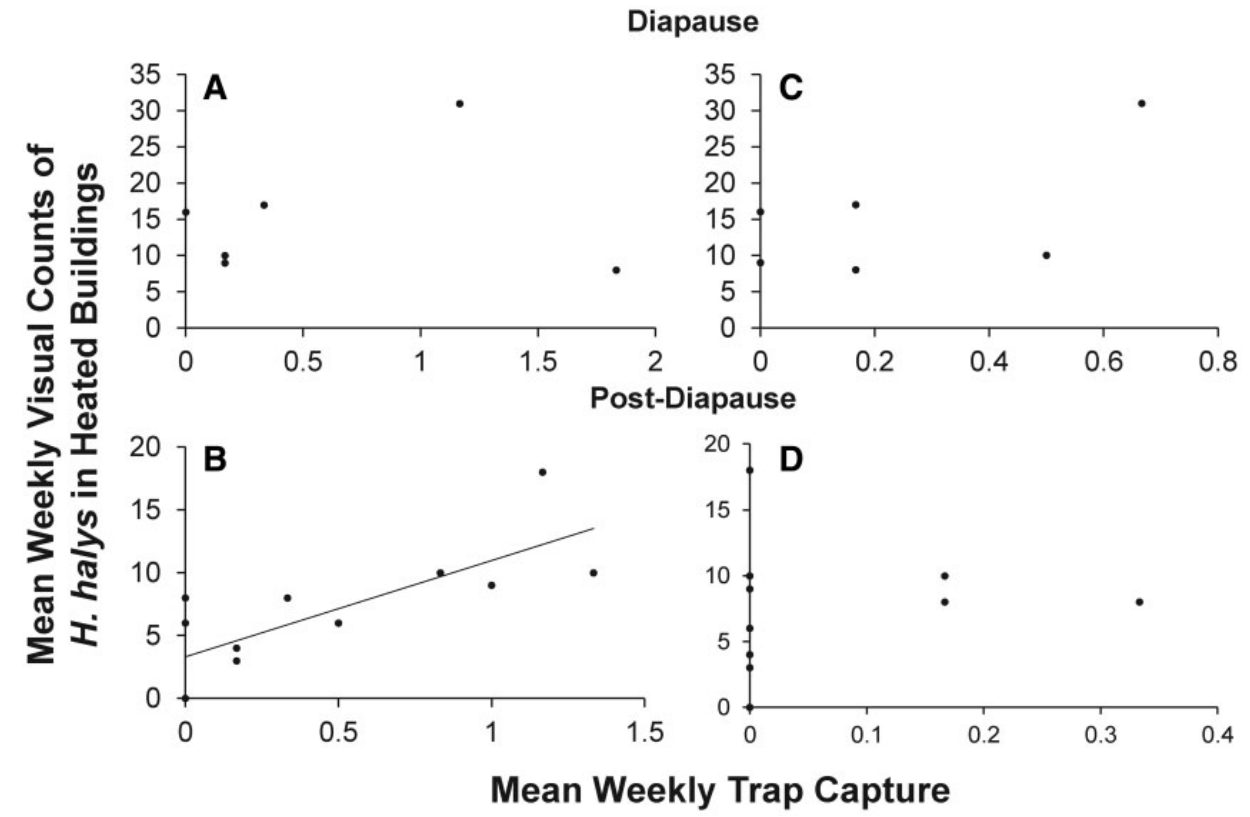

Fig. 2. Correlation between visual survey of $H$. halys abundance and small pyramid traps deployed inside heated structures at the Appalachian Fruit Research Station in 2014 that were baited in the (A) diapause, and (B) postdiapause periods, and those that were unbaited (controls) in the (C) diapause, and (D) postdiapause period. Lines are only plotted on graphs with significant correlations (Spearman Rank Correlation, $\alpha=0.05$ ).

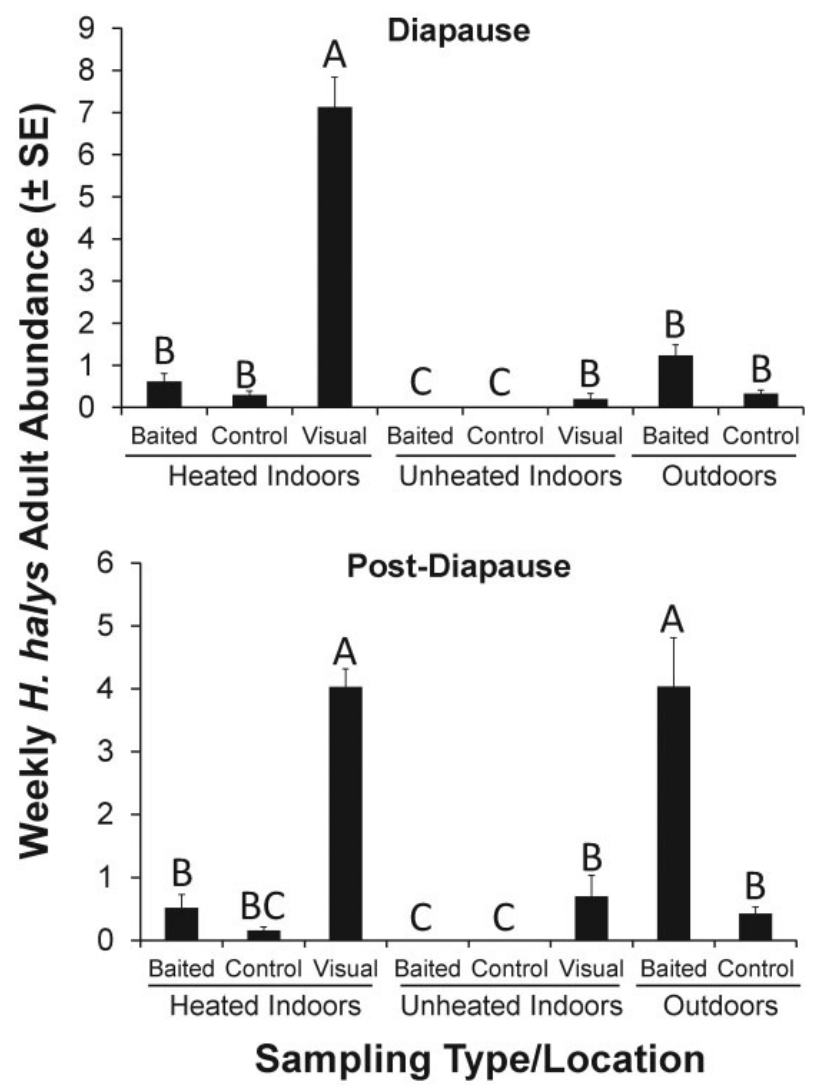

Fig. 3. Mean abundance of $H$. halys from trapping and visual survey data from within heated or unheated structures, as well as outside of buildings at six sites in North Carolina, Virginia, and West Virginia during 2016 in the diapause (top panel) and postdiapause period (bottom panel). Bars with shared letters are not significantly different from each other (Tukey's HSD, $\alpha=0.05$ ). it was $18.5 \pm 0.06^{\circ} \mathrm{C}$. In 2016 , the mean outdoor temperature in the diapause period was $3.5 \pm 2^{\circ} \mathrm{C}$; in the postdiapause period, it was $17.1 \pm 2^{\circ} \mathrm{C}$.

\section{Discussion}

To our knowledge, this is the first evaluation of the use of pheromone-baited traps inside heated and unheated structures for the purposes of surveillance and control. However, despite robust $H$. halys adult activity in the heated buildings that were sampled via visual surveys, pheromone-baited traps captured only a small fraction of these individuals, ranging from $8 \%$ of the active adults during the diapause period to $20 \%$ of adults in the postdiapause period. Aigner and Kuhar (2014) showed that a pan trap containing soapy water with a light suspended above it was more effective at removing $H$. halys from homes than two commercially available traps and one homemade trap. The mean weekly capture in their pan traps was 3-20 adults per trap, whereas the mean captures in pheromonebaited traps in heated buildings for this study was $0.2-0.6$ (e.g., 5-100 times less, though the absolute density in either case is unknown).

Notably, active $H$. halys populations indoors did not correspond with adult captures in traps located outside buildings. The mean temperature from local weather stations across the study sites during the diapause period at sampling locations in 2016 was $3.5^{\circ} \mathrm{C}$, and during the postdiapause period, it was $17.1^{\circ} \mathrm{C}$. Lee et al. (2015) demonstrated that only $3 \%$ of $H$. halys adults will fly when the ambient temperature is $10-15^{\circ} \mathrm{C}$, and sustained flight requires temperatures $>17^{\circ} \mathrm{C}$. As a consequence, wild adults within the vicinity of our sampling locations were probably not very active during the diapause period, and we can assume adults moving from inside to outside would do so through walking and short flight bursts. Because captures in outdoor pyramid traps were not correlated with adult 


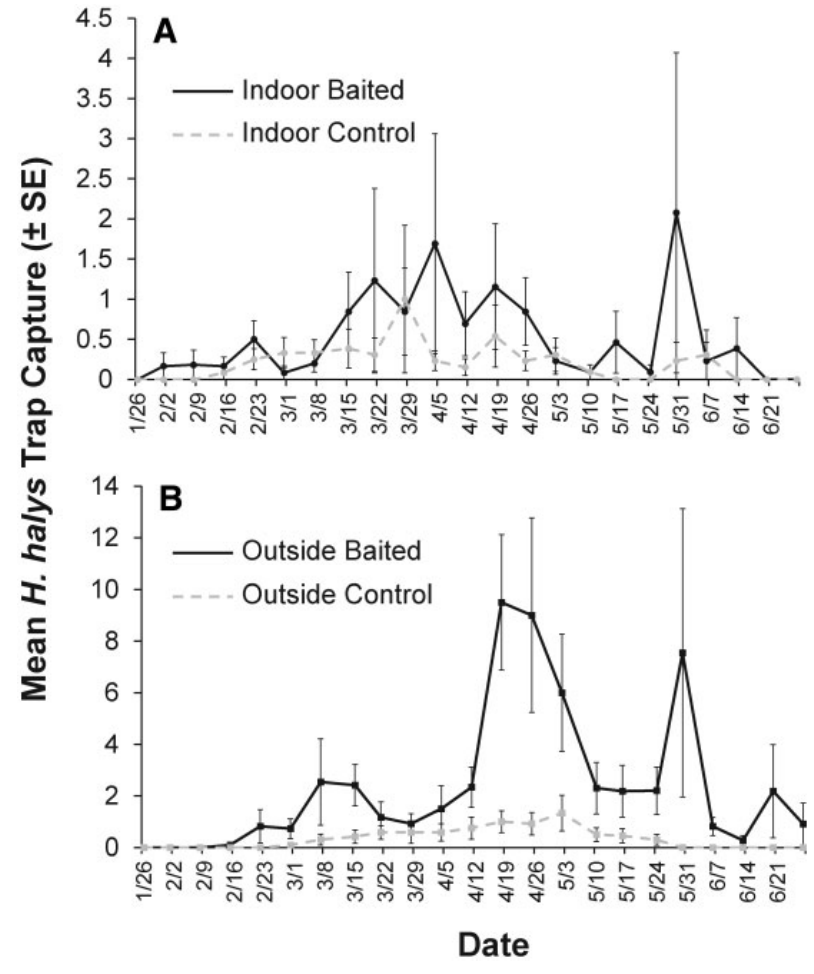

Fig. 4. Weekly abundance of $H$. halys from indoor traps deployed (A) inside heated structures, and (B) outside buildings at six sites in North Carolina, Virginia, and West Virginia during 2016. Dashed grey lines represent unbaited control traps, while solid black lines represent baited traps. Bars on each point represent standard errors.

activity indoors, especially during the diapause period when indoor bug activity was higher, outdoor pyramid traps are probably not effective at intercepting indoor populations.

Management of nuisance pest populations using attractive baits is common for other species, such as termites (Blattodea), where baits contain hexaflumuron or noviflumuron. These have been shown to eliminate all detectable subterranean termite activity ( $\mathrm{Su}$ 2003 and reviewed in Rust and Su 2012). Baits are also commonly and successfully used to manage ant (Formicidae) populations, as mortality is usually delayed sufficiently long to inflict significant damage on an entire colony after the bait has been fed to nest mates by foraging workers (e.g., Stringer et al. 1964). However, our study suggests that pheromone-baited traps are insufficient as an indoor control strategy for $H$. halys.

In terms of surveillance, the captures in pheromone-baited traps and unbaited traps were not correlated with the wild $H$. halys population dynamics, regardless of whether the trap was placed inside or outside. This suggests that pheromone-based trapping is not reliable for monitoring $H$. halys populations during overwintering, and is similar to patterns observed for other stink bug species, which stop responding to their pheromone during diapause (Endo et al. 2007, Weber et al. 2017). A 12-d pilot study conducted in May, which was included in a patent, showed that a more polar mix and racemic mix of murgantiol attracted an average of 5-6.5 H. halys adults per trap in homes, which was more than the blank control (Zhang et al. 2014). However, data from our study suggest that the $H$. halys aggregation pheromone (two stereoisomers from the parent murgantiol compound) in combination with the synergist (MDT) are ineffective for reliably trapping wild populations of $H$. halys indoors from January to June.
As $H$. halys adults emerge in the postdiapause period, they become more responsive to foraging stimuli such as the trunkmimicking, black pyramid base (Leskey et al. 2012b) and the aggregation pheromone. Our findings corroborated this in the correlations between visual counts and captures in both baited and unbaited pyramid traps during the postdiapause, but not the diapause period. The postdiapause period corresponded to the critical 13.5-h photoperiod diapause termination threshold (Nielsen et al. 2016). Many insects exhibit behavioral and olfactory plasticity as a result of their physiological state or the abiotic environment (reviewed in Gadenne et al. 2016). For example, response of the pepper weevil, Anthonomus engenii Cano (Coleoptera: Curculionidae), to host volatiles increased with age and sexual maturation (Adesso and McAuslane 2009). Likewise, abiotic factors such as photoperiod and temperature are important in determining the population dynamics of $H$. halys (Nielsen et al. 2016) and its physiological state (reviewed in Lee et al. 2013). Specifically, H. halys is not sexually mature upon emergence from overwintering sites until a critical day length is reached, which triggers ovarian development (Nielsen et al. in review). This, or another change in physiological state or abiotic factors, may result in the activation of foraging behavior by adult $H$. halys. The largest increase in captures was in pheromone-baited traps located outside, during the postdiapause period. Prior work has demonstrated that marked $H$. halys were not captured in pheromone-baited traps as they emerged from overwintering shelters $\sim 10 \mathrm{~m}$ away although wild (unmarked) adults were captured in these same traps, and they presumably arrived from farther distances after becoming responsive to pheromonal stimuli (Bergh et al. 2017). This may suggest that $H$. halys adults must make a dispersal flight to truly start responding to the pheromone. Preliminary work has demonstrated that $H$. halys individuals which have the opportunity for a dispersal flight live longer and reproduce earlier than those that do not have the opportunity (W.R.M. and T.C.L, unpublished data). For example, there is a large difference between the responses of adults to baited traps outside in the postdiapause period compared with those inside heated or unheated shelters (Fig. 3). Nonetheless, other as-yet-unknown behavioral or physiological mechanisms may be involved in triggering $H$. halys to respond to its aggregation pheromone.

This study examined the response of adult $H$. halys to pheromone-baited traps under gradual natural changes in day length and temperature associated with the transition from winter (diapause) to spring (postdiapause) in the Mid-Atlantic United States within anthropogenic structures. However, $H$. halys is an ongoing biosecurity threat to several countries that do not have reproducing populations in the Southern Hemisphere, including New Zealand and Australia (MacLellan 2013), with drastically different day length and temperatures compared with the Northern Hemisphere at any given point in time. One of the primary interception routes for adult $H$. halys is aboard cargo container ships, where the journey from the eastern United States to New Zealand requires about $30 \mathrm{~d}$ (https://www.searates.com/reference/portdistance/). It is known that $H$. halys responds to its aggregation pheromone and MDT synergist in traps during the growing season elsewhere in the world (Morrison et al. 2017b). However, as a ship travels to the southern hemisphere, overwintering $H$. halys would experience rapid changes in day length and temperature, and it is unknown how long it would take $H$. halys to start responding to pheromonal stimuli under a regime with rapidly shifting abiotic conditions.

There are still many outstanding questions regarding the spring emergence behavior of adult $H$. halys. Of particular interest are 1) a better understanding of the precise trigger for its response to 


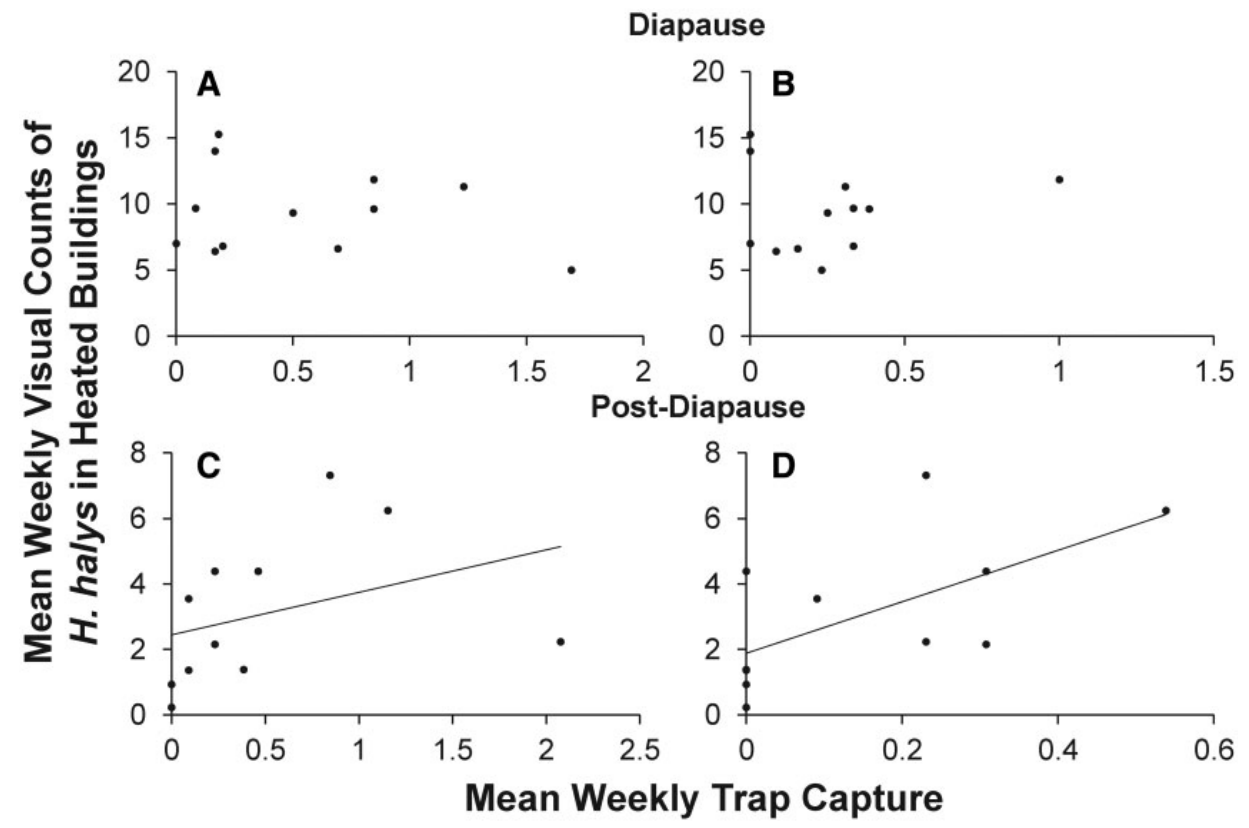

Fig. 5. Correlation between mean abundance of $H$. halys found through visual surveys and mean small pyramid trap capture inside heated structures that were baited in the (A) diapause and (C) postdiapause period, and those that were unbaited (controls) in the (B) diapause and (D) postdiapause period deployed at six sites in North Carolina, Virginia, and West Virginia in 2016. Lines are only plotted on graphs with significant correlations (Spearman rank correlation, $\alpha=0.05$ ).

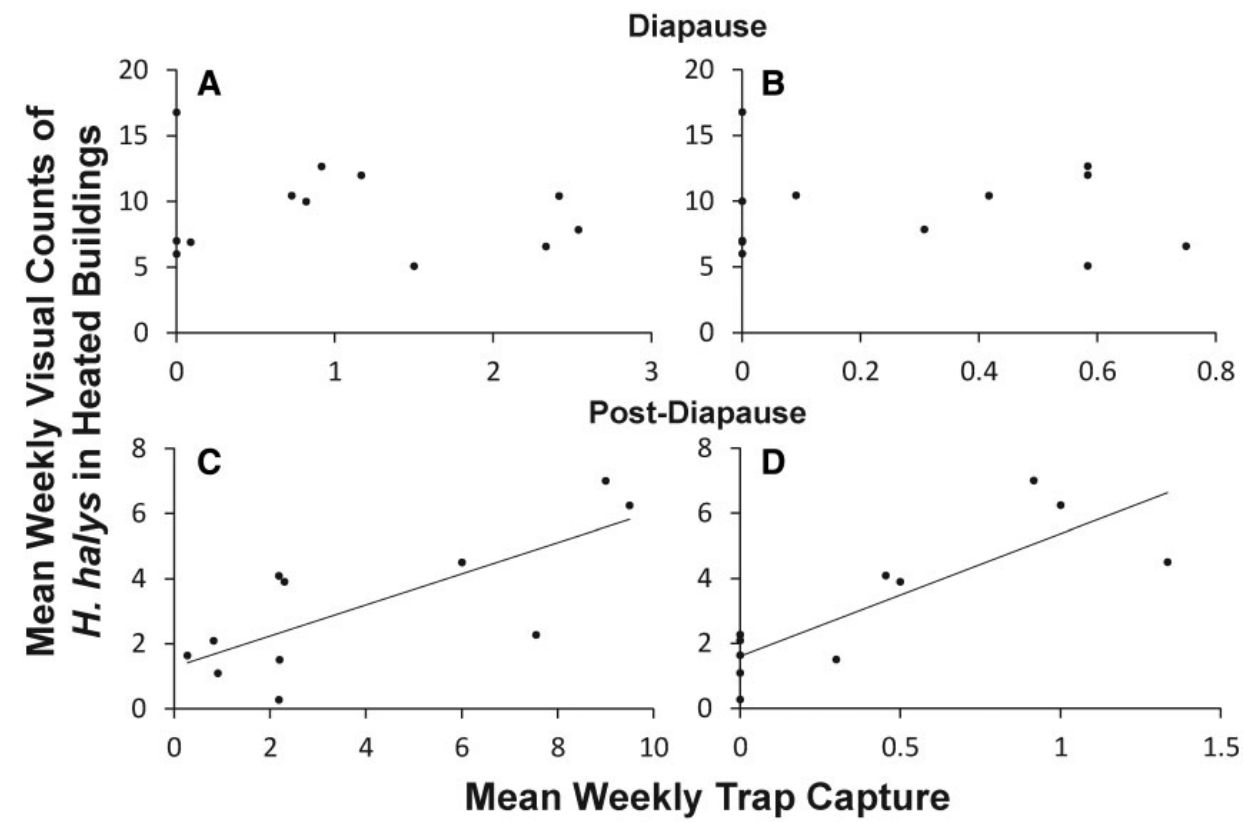

Fig. 6. Correlation between mean abundance of $H$. halys found through visual surveys and mean large pyramid trap capture outside structures that were baited in the (A) diapause and (C) postdiapause period, and those that were unbaited (controls) in the (B) diapause and (D) postdiapause period deployed at four sites in North Carolina, Virginia, and West Virginia in 2016. Lines are only plotted on graphs with significant correlations (Spearman rank correlation, $\alpha=0.05$ ).

pheromonal and foraging stimuli, including whether dispersal flights are required, 2) how $H$. halys responds to its pheromone during cargo voyages to the southern hemisphere under forced spring-like conditions, and 3) elucidating whether other semiochemicals or other communication modalities are used by $H$. halys during the spring emergence or fall dispersal periods to orient to or from anthropogenic structures while adults are not responsive to their aggregation pheromone or MDT pheromone synergist. A greater understanding of these factors will aid researchers in better understanding the population dynamics of $H$. halys over the season, as well as support the management of nuisance issues associated with the pest.

\section{Acknowledgments}

We would like to thank the excellent technical assistant of McKenzie Allen (USDA-ARS), John Cullum (USDA-ARS), Jean Engelman (Virginia Tech), Elizabeth Fread (Virginia Tech), Torri Hancock (USDA-ARS), Jamie Hogue (Virginia Tech), Adam Morehead (Virginia Tech), Brittany Poling 
(USDA-ARS), and Steve Schoof (NC State University). This project was funded by a USDA NIFA SCRI CAP Grant 2016-51181-25409. The use of trade names is for the purposes of providing scientific information only, and does not constitute endorsement by the United States Department of Agriculture. The USDA is an equal opportunity employer.

\section{References Cited}

Adesso, K. N., and H. J. McAuslane. 2009. Pepper weevil attraction to volatiles from host and nonhost plants. Environ. Entomol. 38: 216-224.

Aigner, J., and T. P. Kuhar. 2014. Using citizen scientists to evaluate light traps for catching brown marmorated stink bugs in homes in Virginia. J. Ext. 52: 1-9.

Aigner, J. D., and T. P. Kuhar. 2016. Lethal high temperature extremes of the brown marmorated stink bug (Hemiptera: Pentatomidae) and efficacy of commercial heat treatments for control in export shipping cargo. J. Agric. Urban Entomol. 32: 1-6. doi:10.3954/1523-5475-32.1.1.

Bergh, C. J., R. Morrison, III, S. V. Joseph, and T. C. Leskey. 2017. Characterizing spring emergence of adult Halyomorpha halys (Hemiptera: Pentatomidae) using experimental overwintering shelters and commercial pheromone traps. Entomol. Exp Appl. doi: 10.1111/eea.12539. (in press).

Endo, N., T. Yasuda, K. Matsukur, T. Wada, S. E. Muto, and R. Sasaki. 2007. Possible function of Piezodorus hybneri (Heteroptera: Pentatomidae) male pheromone: Effects of adult age and diapause on sexual maturity and pheromone production. Appl. Entomol. Zool. 42: 637-641.

Gadenne, C., R. B. Barrozo, and S. Anton. 2016. Plasticity in insect olfaction: To smell or not to smell? Annu. Rev. Entomol. 61: 317-333.

Haye, T., T. Gariepy, K. A. Hoelmer, J. Rossi, J. Streito, X. Tassus, and N. Desneux. 2015. Range expansion of the invasive brown marmorated stinkbug, Halyomorpha halys: An increasing threat to field, fruit and vegetable crops worldwide. J. Pest Sci. 88: 665-673.

Hoebeke, E. R., and M. E. Carter. 2003. Halyomorpha halys (Stål) (Heteroptera: Pentatomidae): A polyphagous plant pest from Asia newly detected in North America. Proc. Entomol. Soc. Wash. 105: 225-237.

Inkley, D. B. 2012. Characteristics of home invasion by the brown marmorated stink bug (Hemiptera: Pentatomidae). J. Entomol. Sci. 47: 125-130.

Khrimian, A., A. Zhang, D. C. Weber, H. Y. Ho, J. R. Aldrich, K. E. Vermillion, M. A. Siegler, S. Shirali, F. Guzman, and T. C. Leskey. 2014. Discovery of the aggregation pheromone of the brown marmorated stink bug (Halyomorpha halys) through the creation of stereoisomeric libraries of 1-bisabolen-3-ols. J. Nat. Prod. 77: 1708-1717.

Kuhar, T. P., D. Short, G. Krawczyk, and T. C. Leskey. 2017. Deltamethrinincorporated nets as an integrated pest management tool for the invasive Halyomorpha halys (Hemiptera: Pentatomidae). J. Econ. Entomol. 1-3, doi: 10.1093/jee/tow321. (in press).

Lee, D. H., D. Short, S. V. Joseph, J. C. Bergh, and T. C. Leskey. 2013. Review of the biology, ecology, and management of Halyomorpha halys (Hemiptera: Pentatomidae) in China, Japan, and the Republic of Korea. Environ. Entomol. 42: 627-641.

Lee, D. H., P. Cullum, J. L. Anderson, J. L. Daugherty, L. M. Beckett, and T. C. Leskey. 2015. Characterization of overwintering sites of the invasive brown marmorated stink bug in natural landscapes using human surveyors and detector canines. PLoS ONE 9: e91575.

Leskey, T. C., D. Short, B. R. Butler, and S. E. Wright. 2012a. Impact of the invasive brown marmorated stink bug, Halyomorpha halys (Stål), in midAtlantic tree fruit orchards in the United States: Case studies of commercial management. Psyche 2012: 1-14. doi:10.1155/2012/535062

Leskey, T. C., E. Wright, B. D. Short, and A. Khrimian. 2012b. Development of behaviorally-based monitoring tools for the brown marmorated stink bug (Heteroptera: Pentatomidae) in commercial tree fruit orchards. J Entomol Sci. 47: 76-85

Leskey, T. C., A. Agnello, J. C. Bergh, G. P. Dively, G. C. Hamilton, P. Jentsch, A. Khrimian, G. Krawczyk, T. P. Kuhar, D.-H. Lee, et al. 2015a.
Attraction of the invasive Halyomorpha halys (Hemiptera: Pentatomidae) to traps baited with semiochemical stimuli across the United States. Environ. Entomol. 44: 746-756.

Leskey, T. C., A. Khrimian, D. C. Weber, J. R. Aldrich, B. D. Short, D.-H. Lee, and W. R. Morrison III. 2015b. Behavioral responses of the invasive Halyomorpha halys (Stal) to traps baited with stereoisomeric mixtures of 10,11-epoxy-1-bisabolen-3-ol. J. Chem. Ecol. 41: 418-429.

Leskey, T. C., H. Lee, D. M. Glenn, and W. R. Morrison III. 2015c. Behavioral responses of the invasive Halyomorpha halys (Stål) (Hemiptera: Pentatomidae) to light-based stimuli in the laboratory and field. J. Insect Behav. 28: 674-692.

MacLellan, R. 2013. Brown marmorated stink bug: A potential risk to New Zealand. Surveillance 40.

Mooneyham, K. L., J. Aigner, and T. P. Kuhar. 2016. Control of brown marmorated stink bug with insecticide-treated window screens, 2015. Arthropod Manage. Tests 1: 1.

Morrison, III W. R., J. P. Cullum, and T. C. Leskey. 2015. Evalulation of trap designs and deployment strategies for capturing Halyomorpha halys (Hemiptera: Pentatomidae). J. Econ. Entomol. 108: 1683-1692.

Morrison, III W. R., A. N. Bryant, B. Poling, N. F. Quinn, and T. C. Leskey. 2017a. Predation of Halyomorpha halys (Hemiptera: Pentatomidae) from web-building spiders associated with anthropogenic dwellings. J. Insect Behav. 30: 70-85.

Morrison, III W. R., C-G. Park, B. Y. Seo, Y.-L. Park, H. G. Kim, K. B. Rice, D.-H. Lee, and T. C. Leskey. 2017b. Attraction of the invasive Halyomorpha halys in its native Asian range to traps baited with semiochemical stimuli. J. Pest Sci. doi: 10.1007/s10340-016-0816-x. (in press).

Nielsen, A. L., K. Holmstrom, G. C. Hamilton, J. Cambridge, and J. IngersonMahar. 2013. Use of black light traps to monitor the abundance, spread, and flight behavior of Halyomorpha halys (Hemiptera: Pentatomidae). J. Econ. Entomol. 106: 1495-1502.

Nielsen, A. L., S. Chen, and S. J. Fleischer. 2016. Coupling developmental physiology, photoperiod, and temperature to model phenology and dynamics of an invasive heteropteran, Halyomorpha halys. Front. Physiol. 7: 165. doi:10.3389/fphys.2016.00165

R Core Team 2016. R: A language and environment for statistical computing. R Foundation for Statistical Computing, Vienna, Austria. https://www.rproject.org/.

Rice, K. B., C. Bergh, E. J. Bergmann, D. J. Biddinger, C. Dieckhoff, G. P. Dively, H. Fraser, T. Gariepy, G. C. Hamilton, T. Haye, et al. 2014. Biology, ecology, and management of brown marmorated stink bug (Hemiptera: Pentatomidae). J. Integr. Pest Manag. 5: 1-13.

Rust, M. K., and N. Y. Su. 2012. Managing social insects of urban importance. Annu. Rev. Entomol. 57: 355-375.

Short, B. D., A. Khrimian, and T. C. Leskey. 2016. Pheromone-based decision support tools for mangement of Halyomorpha halys in apple orchards: Development of a treatment threshold. J. Pest Sci. doi:10.1007/s10340-0160812-1. (in press).

Stringer, C. E., S. Lofgren, and F. J. Bartlett. 1964. Imported fire ant toxic bait studies: Evaluation of toxicants. J. Econ. Entomol. 57: 941-945.

Su, N. Y. 2003. Baits as a tool for population control of the Formosan subterranean termite. Sociobiology 41: 177-192.

Weber, D. C., C. Leskey, G. C. Walsh, and A. Khrimian. 2014. Synergy of aggregation pheromone with methyl $(E, E, Z)-2,4,6$-decatrienoate in attraction of Halyomorpha halys (Hemiptera: Pentatomidae). J. Econ. Entomol. 107: 1061-1068.

Weber, D. C., A. Khrimian, M. C. Blassioli-Moraes, and J. G. Millar, 2017. Semiochemistry of Pentatomoidea. In: J. McPherson (eds.), Biology of Invasive Stink Bugs and Related Species CRC Press, in press.

Zhang, Q. H., R. G. Schneidmiller, G. Zhou, and D. R. Hoover. 2014. Murgantiol as an indoor stink bug attractant. USA Patent US 8,663,619 B2. 